'Sección de Reumatología, Servicio de Medicina Hospital del Salvador, Universidad de Chile. Santiago, Chile. ${ }^{2}$ Servicio de Medicina Hospital del Salvador, Universidad de Chile. Santiago, Chile.

Fuente de apoyo financiero: ninguna.

Recibido el 23 de diciembre de 2013, aceptado el 1 de abril de 2014. Correspondencia a: Dr. Daniel Erlij Avenida Salvador 364, Providencia, Sección Reumatología.

9-2226708, 25753590. danerlij@gmail.com

\section{Enfermedad relacionada a IgG4, el nuevo "gran simulador": caso clínico}

\author{
DANIEL ERLIJ ${ }^{1}$, DANIEL RAMOS ${ }^{2}$, JACQUELINE MONTAÑA ${ }^{2}$, \\ PAULA KUSNIR ${ }^{1}$, GONZALO CORREA ${ }^{2}$, OSCAR NEIRA ${ }^{1}$
}

\section{IgG4-related disease, the new "great mimicker". Report of one case}

Due to its multisystem involvement, IgG4 -related disease should be considered in the differential diagnosis of medical conditions such as lymphadenopathies, aortitis, serositis and retroperitoneal fibrosis. It shares features with other entities historically described as "great mimickers" such as syphilis, tuberculosis, sarcoidosis, and systemic lupus erythematosus. We report a 40 year-old male with recurrent effusive - constrictive pericarditis, lymphadenopathy and aortitis. The study revealed an inactive tuberculosis with negative cultures for acid fast bacilli. The patient had high serum levels of IgG4 and a mediastinal lymph node biopsy was consistent with IgG4 -related disease. The patient was treated with prednisone $40 \mathrm{mg} /$ day with an excellent response.

(Rev Med Chile 2014; 142: 646-650)

Key words: Aortitis; Immunoglobulin G; Lymphatic diseases.
$\mathrm{E}$ n medicina existen entidades de afección multisistémica denominadas "grandes simuladores", por la amplia gama de manifestaciones clínicas que expresan. Históricamente, en la lucha por el título del gran simulador, ha sido la sífilis quien ha llevado el primer lugar, debido a su amplia expresión clínica ${ }^{1}$. Muy de cerca se encuentra la tuberculosis ${ }^{2}$. En la actualidad, la enfermedad relacionada a IgG4 (ER-IgG4) ha ido tomando cada vez más importancia en medicina y la literatura médica, llegando a posicionarse como "el nuevo gran simulador" se han publicado casos de ER-IgG4 simulando meningiomas múltiples ${ }^{4}$, colangiocarcinoma ${ }^{5}$ y cáncer de páncreas ${ }^{6}$.

La ER-IgG4 es una entidad fibro inflamatoria sistémica que fue descrita por primera vez en 1961 en contexto de pancreatitis asociada a hipergammaglobulinemia, pero no fue sino hasta el año 2001, cuando autores japoneses relacionaron dicha entidad a la IgG4 $4^{7,8}$. Recién en el año 2011, un consenso internacional llevado a cabo en Boston definió los criterios y la denominación actual de la enfermedad ${ }^{9}$.

\section{Caso clínico}

Varón de 40 años, sondista de minería. Tiene antecedentes de eritema nodoso de etiología no precisada en 1995 y serología positiva para enfermedad de Chagas el año 2011, realizada a raíz de una cardiomegalia radiológica. Presentaba desde febrero de 2013, un cuadro de edema de extremidades inferiores que progresa con compromiso escrotal. La evaluación ecocardiográfica detectó un extenso derrame pericárdico sin signos de taponamiento, realizándose una pericardiocentesis con extracción de $840 \mathrm{cc}$ de líquido citrino, con análisis microbiológicos negativos. Debido a la rápida reproducción del derrame, se realizó una ventana pericárdica. La biopsia de tejido pericárdico evidenció un infiltrado de predominio linfoplasmocitario y focos de microhemorragia. El análisis inmunohistoquímico determinó la policlonalidad del infiltrado. La tomografía computada de cuello, tórax, abdomen y pelvis reveló una pansinusitis, múltiples adenopatías mediastínicas, mesentéricas y retroperitoneales, derrame pericárdico con signos de pericarditis crónica, 
derrame pleural izquierdo, secuelas sugerentes de tuberculosis en el vértice pulmonar derecho y un engrosamiento de la pared de la aorta ascendente, descendente y arco aórtico, sugerente de aortitis (Figura 1). Entre los exámenes de laboratorio, destacó hemoglobina $12,2 \mathrm{~g} / \mathrm{dL}$, plaquetas y leucocitos normales en recuento y fórmula, VHS 46 $\mathrm{mm} / \mathrm{h}$. La función renal y hepática, el examen de orina y el perfil bioquímico no mostraron alteraciones. La lactato deshidrogenasa (LDH) fue de $131 \mathrm{UI} / \mathrm{L}$ (normal 230-460), la albúmina de $3,3 \mathrm{~g} / \mathrm{dL}$ (normal 3,5-5,2) y la $\beta 2$ microglobulina de $2,35 \mathrm{mg} / \mathrm{L}$ (normal 0,8-2,2). El estudio viral fue negativo para VIH, VHB, VHC y HTLV-1. El estudio reumatológico fue negativo para anticuerpos antinucleares y factor reumatoídeo. El recuento de inmunoglobulinas fue IgA $231 \mathrm{mg} /$ dL (normal 70-400), IgG $1.316 \mathrm{mg} / \mathrm{dL}$ (normal 700-1.600) e IgM 23 mg/dL (normal 40-230). En relación a la lesión cicatricial del ápice pulmonar derecho, tuvo un PPD 27 mm, con Quantiferon positivo y baciloscopias negativas. Ante la falta de un diagnóstico etiológico, se realizó una biopsia de ganglio mediastínico que fue informada como plasmocitosis ganglionar. Por la presencia de poliadenopatías, derrame pericárdico y pleural, aortitis e infiltrado linfoplasmocitario policlonal, se realizó una determinación de subclases de IgG, que evidenció elevación de IgG4 en 156 mg/dL (normal 6,1-121). El análisis inmunohistoquímico para IgG4 del tejido ganglionar fue positivo, con una proporción de células plasmáticas IgG4/IgG de $40 \%$ (Figura 2). Finalmente, el cultivo de Koch del mismo tejido fue negativo.

Se diagnosticó una enfermedad relacionada a IgG4 con compromiso ganglionar, pericárdico, pleural, aórtico y una tuberculosis latente, iniciándose terapia con prednisona $40 \mathrm{mg} /$ día asociado a isoniazida $300 \mathrm{mg} /$ día. Al mes de tratamiento, el control imagenológico evidenció una dramática regresión del derrame pericárdico y pleural, así como también de las adenopatías descritas (Figura 3 ). Respecto a la aortitis, la mejoría fue menos notoria, con disminución parcial del engrosamiento de la pared de la arteria.

\section{Discusión}

La IgG4 constituye menos de 5\% de la IgG total en personas sanas, siendo la menos abundante de las subclases. Al igual que la IgE, su producción es controlada por células Th2. No tiene la capacidad de activar el complemento de manera efectiva, considerándose su rol en el sistema inmune como marginal. En este sentido, debe considerarse la IgG4 como un marcador de enfermedad y no como factor patogénico ${ }^{7}$.

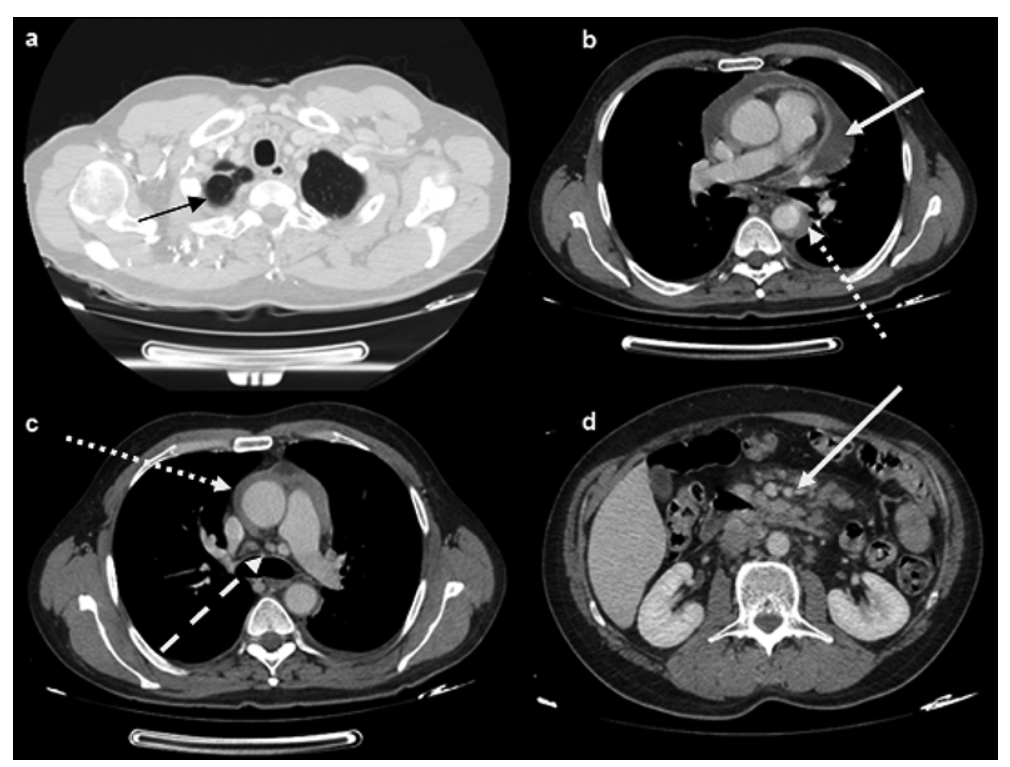

Figura 1. Imágenes de tomografía axial del paciente. La imagen a, evidencia en ventana pulmonar, la lesión cicatricial del ápice derecho. Las imágenes b y c, muestran el engrosamiento de la pared de la aorta (flecha punto cuadrado), el derrame pericárdico (flecha blanca) y las adenopatías mediastínicas (flecha guión). La figura d permite observar las adenopatías mesentéricas. 

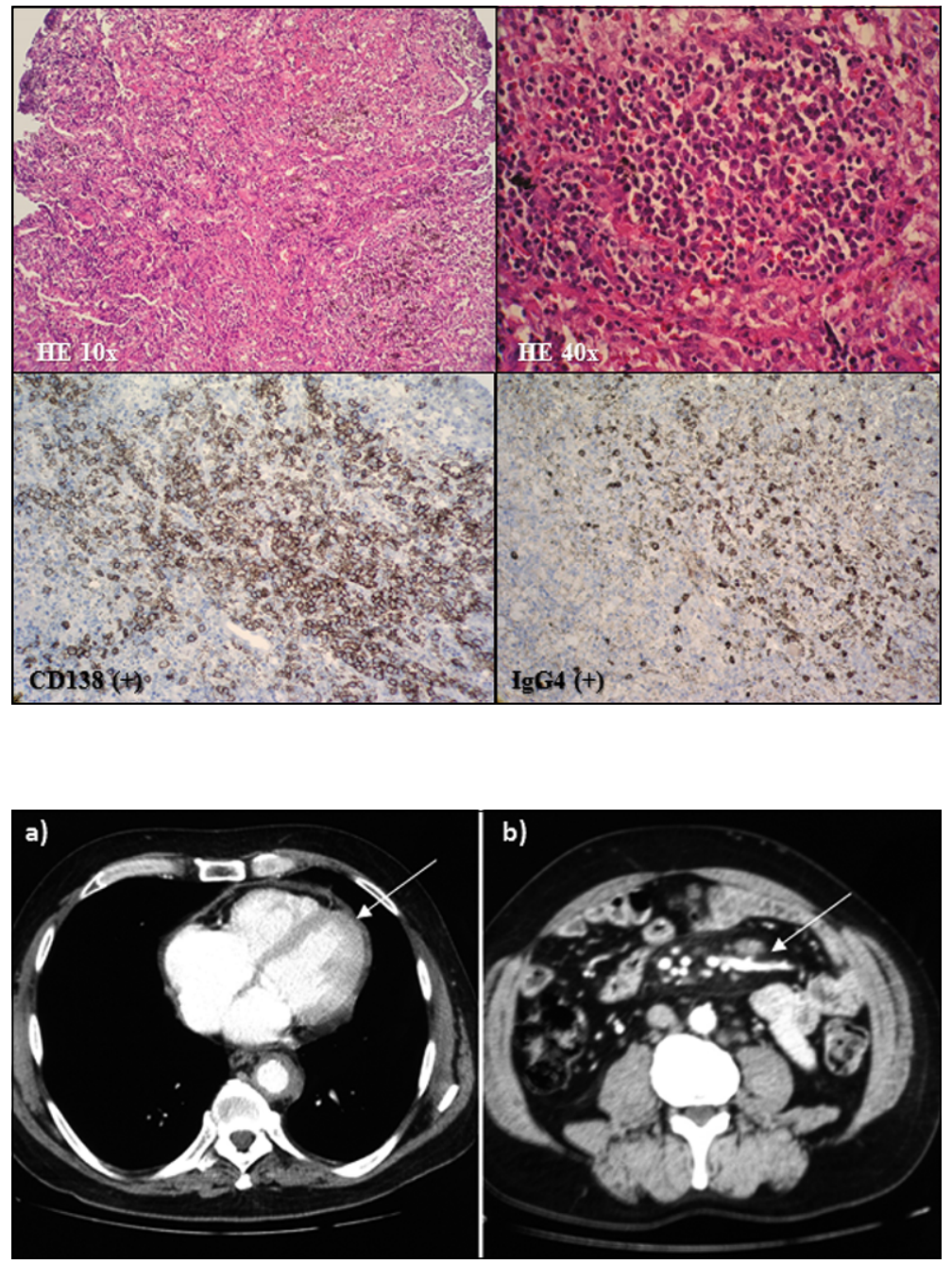

Figura 2. Muestras histológicas de ganglio mediastínico del paciente. Las imágenes superiores muestran infiltrado linfoplasmocitario con tinción hematoxilina eosina a aumentos de 10 y 40x. Las imágenes inferiores corresponden a la inmunohistoquímica, positiva para CD138 (marcador de plasmocitos) e lgG4.
Figura 3. Imágenes de tomografía axial del paciente luego de 1 mes de tratamiento esteroidal. La imagen a, muestra la notable regresión del derrame pericárdico y la imagen b evidencia la importante mejoría de las adenopatías mesentéricas.
La ER-IgG4 suele afectar a varones, generalmente mayores de 50 años, con una relación varón/mujer de 3,7-5,7: 1, excepto en las formas con compromiso de cabeza y cuello, donde la relación se estrecha ${ }^{10}$. Pueden comprometerse uno o más órganos, generalmente de una misma región anatómica, de manera sincrónica o metacrónica. Los principales blancos incluyen una larga lista encabezada por el páncreas, seguido por los ganglios linfáticos, la vía biliar, las glándulas salivales y lagrimales, riñones, aorta, retroperitoneo y sistema respiratorio. La principal manifestación consiste en un edema pseudotumoral focal o difuso de un órgano. El inicio puede ser subagudo, generalmente no asociado a síntomas constitucionales. Hasta
$40 \%$ de los pacientes puede presentar asociación a manifestaciones alérgicas tales como rinitis, asma y sinusitis crónica ${ }^{11}$, esta última presente en este paciente.

El compromiso pancreático de la ER-IgG4 fue el primero y más frecuentemente descrito, bajo la forma de pancreatitis autoinmune con una presentación clínica caracterizada por ictericia afebril e indolora, asociada a engrosamiento difuso o parcial del páncreas, con adenopatías relacionadas en $80 \%$ de los casos. Este cuadro clínico, altamente sugerente de un cáncer de páncreas, es una de las clásicas y más conocidas simulaciones de la ER-IgG4 ${ }^{12}$.

La afección ganglionar, manifestación clave 
en nuestro paciente, se ha descrito en asociación al órgano comprometido y bajo la forma de poliadenopatías. Es importante destacar el hecho de que en estos casos, la LDH suele estar normal o levemente elevada, factor de gran relevancia considerando al linfoma como diagnóstico diferencial ${ }^{11}$. Dicha situación fue de gran importancia en el caso descrito, en el cual la LDH se encontró incluso bajo el valor normal.

La aortitis relacionada a IgG4 se describió inicialmente afectando a la aorta abdominal, pero se conoce actualmente el compromiso de la aorta torácica, en especial del arco aórtico. Se asocia a veces a dilatación aneurismática, generalmente a nivel abdominal y fibrosis periaórtica. El compromiso aórtico en contexto de ER-IgG4 puede ser muy difícil de diagnosticar, en especial cuando no existe compromiso de otros órganos susceptibles de una biopsia. Es importante considerar que, en este contexto, se ha descrito $33 \%$ de compromiso de otros órganos en aortitis torácica, situación vista en nuestro paciente, y $29 \%$ en la forma de presentación de aneurisma abdominal ${ }^{13}$.

El compromiso pericárdico ha sido descrito bajo la forma de derrame pericárdico y de pericarditis constrictiva, como en el caso presentado, siendo una manifestación muy infrecuente $e^{14}$.

El diagnóstico de la ER-IgG4 se basa en tres pilares: El clínico-radiológico, representado por la presencia de edema o formación de masa asociado a uno o más órganos; el serológico, referido a la elevación sérica de IgG4 con valores mayores o iguales a $135 \mathrm{mg} / \mathrm{dL}$ y el histológico, basado en la presencia de fibrosis estoriforme, infiltración tisular linfoplasmocitaria o la presencia de más de 10 plasmocitos IgG4 $(+)$ por campo mayor con una razón IgG4/IgG mayor a 40\%. El diagnóstico definitivo se consigue con los tres criterios presentes (como en el caso presentado), el diagnóstico probable; con el clínico-radiológico más el histológico y el diagnóstico posible con el clínico-radiológico más el serológico' ${ }^{9}$ La relativa menor relevancia del criterio serológico que queda de manifiesto, se debe en parte a la observación de que hasta $30 \%$ de los casos de ER-IgG4 puede tener niveles de esta inmunoglobulina en rango normal ${ }^{7}$.

Existen dos esquemas terapéuticos sugeridos. El japonés, que emplea prednisona en dosis de 0,6 $\mathrm{mg} / \mathrm{Kg}$ /día por 2 a 4 semanas, con disminución progresiva hasta llegar a $5 \mathrm{mg}$ /día a los 3-6 meses, extendiendo la dosis de mantención hasta 3 años.
El segundo esquema, descrito en la Clínica Mayo, emplea prednisona $40 \mathrm{mg}$ /día por 4 semanas, con disminución progresiva hasta suspensión en 3 meses. La tasa de recaída con estos esquemas se ha descrito hasta en 50\%, lo cual ha sugerido el uso de terapias asociadas como metotrexato, azatioprina, micofenolato ${ }^{15} \mathrm{y}$ más recientemente rituximab ${ }^{16}$. El seguimiento de los pacientes con niveles séricos de IgG4 para evaluar respuesta al tratamiento o predecir recaídas, no es de gran utilidad. Un estudio multicéntrico japonés demostró que los niveles de IgG4 no disminuyeron en 63\% de los pacientes tratados con corticoides, a pesar de una buena respuesta clínica y radiológica ${ }^{17}$.

Si consideramos que los principales diagnósticos diferenciales de la ER-IgG4 constituyen patologías de tipo infecciosas como la tuberculosis, neoplásicas como los linfomas y tumores de páncreas, y reumatológicas como la sarcoidosis y el lupus eritematoso sistémico ${ }^{3}$, es fácil entender las dificultades diagnósticas de esta enfermedad, la que debemos tener presente en la actualidad, como el nuevo gran simulador de la medicina.

\section{Referencias}

1. Fitzgerald F. The great imitator, Syphilis. West J Med 1981; 140 (5): 424-32.

2. Maurice L, Sievers M. The second "great imitator"Tuberculosis. JAMA 1961; 176 (9): 809-10.

3. Pérez R, Espinoza L, Zea A. The great mimicker: IgG4related disease. Clin Rheumatol 2013; 32 (7): 1267-73.

4. Nishino T, Toda J, Nakatsuka T, Kimura T, Inaoka T, Terada H. IgG4-related inflammatory pseudotumors mimicking multiple meningiomas. Jpn J Radiol 2013; 31 (6): 405-7.

5. Nguyen-tat M, Gamstätter T, Marquardt JU, Geißinger E, Schadmand-Fischer S, Lang, $\mathrm{H}$ et al. IgG4-related sclerosing cholangitis mimicking cholangiocarcinoma. Z Gastroenterol 2012; 50 (9): 1008-12.

6. Gong PL, Liu TT, Shen XZ. Differentiation of autoimmune pancreatitis with pancreatic carcinoma remains a challenge to physicians. J Dig Dis 2012; 13 (5): 267-73.

7. Stone JH, Zen Y, Deshpande V. IgG4-related disease. N Engl J Med 2012; 366 (6): 539-51.

8. Hamano H, Kawa S, Horiuchi A, Unno H, Furuya N, Akamatsu T, et al. High serum IgG4 concentrations in patientswith sclerosing pancreatitis. N Engl J Med 2001; 344: 732-8.

9. Umehara H, Okazaki K, Masaki Y, Kawano M, Yamamo- 
to $\mathrm{M}$, Saeki T, et al. Comprehensive diagnostic criteria forIgG4-related disease 2011. Mod Rheumatol 2011; 22: 21-30.

10. Zen Y, Nakanuma Y. IgG4-related disease: a crossreactional study of 114 cases. Am J Surg Pathol 2010; 34: 1812-9.

11. Guma M, Firestein GS. IgG4-related diseases. Best Pract Res Clin Rheumatol 2012; 26: 425-38.

12. Park DH, Kim MH, Chari ST. Recent advances in autoimmune pancreatitis. Gut 2009; 58: 1680-9.

13. Stone JH. Aortitis, periaortitis, and retroperitoneal fibrosis, as manifestations of IgG4-related systemic disease. Curr Opin Rheumatol 2010; 23: 88-94.
14. Sekiguchi H, Horie R, Suri RM, Yi ES, Ryu JH. Constrictive Pericarditis Caused by Immunoglobulin G4-Related Disease. Circ Heart Fail 2012; 5: 30-1.

15. Khosroshahi A, Stone JH. Treatment approaches to IgG4-related systemic disease. Curr Opin Rheumatol 2010; 23: 67-71.

16. Khosroshahi A, Carruthers MN, Deshpande V, Unizony $\mathrm{S}$, Bloch DB, Stone JH. Rituximab for the treatment of IgG4-related disease: lessons from 10 consecutive patients. Medicine (Baltimore) 2012; 91: 57-66.

17. Kamisawa T, Shimosegawa T, Okazaki K, Nishino T, Watanabe H, Kanno A, et al. Standard steroid treatment for autoimmune pancreatitis. Gut 2009; 58: 1504-7. 